\title{
Effect of component stiffness and deformation on vehicle lateral drift during braking
}

\author{
N Mirza ${ }^{1}$, K Hussain ${ }^{1 *}$, A J Day ${ }^{1}$, and J Klaps ${ }^{2}$ \\ ${ }^{1}$ School of Engineering Design and Technology, University of Bradford, Bradford, UK \\ ${ }^{2}$ Ford Motor Company, Genk, Belgium
}

The manuscript was received on 8 July 2008 and was accepted after revision for publication on 26 November 2008.

DOI: 10.1243/14644193JMBD175

\begin{abstract}
This article presents a simulation study into effects of compliant (flexible) components (such as the engine subframe and the lower control arm) and their deflections on the characteristics of a vehicle experiencing steering drift during straight-line braking. The vehicle front and rear suspension are modelled using multi-body dynamic analysis software. The front suspension model represents the MacPherson strut design of the vehicle and includes a rack and pinion steering system, brake system, engine subframe, and a powertrain unit. The model has been analysed under two steering control methods: fixed and free control. Suspension characteristics and the effect of deflections arising from the subframe and the lower control arm on these suspension characteristics have been analysed.

The simulations confirmed that variation of component stiffness and interactions within components give rise to side-to-side deflections that could affect lateral drift during braking. It is concluded that side-to-side variation of suspension characteristics can have a detrimental effect on lateral drift during braking and that compliant components whose stiffness varies from side to side can cause different side-to-side deflections that can induce and influence variation in suspension characteristics such as toe steer angle that can lead the vehicle during braking.
\end{abstract}

Keywords: Automatics Dynamics Analysis of Mechanical System (ADAMS), multi-body dynamics, braking, steering, drift, compliance, deflections

\section{INTRODUCTION}

The primary purpose of automotive brakes is to provide retardation when required to the motion of a vehicle such that it can be decelerated, if necessary to rest, within an appropriate distance. When brakes are applied, the retarding force on the vehicle is generated at the tyre/road contact patch and the braking force generated defines the vehicle's ability to achieve the required deceleration within the required distance, also the behaviour of the vehicle while braking [1]. Vehicle behaviour or response during braking is an important factor in road safety, because brake systems are designed to produce maximum braking effectiveness in order to achieve minimum stopping distances

\footnotetext{
*Corresponding author: School of Engineering, Design \& Technology, University of Bradford, Bradford, West Yorkshire BD7 1DP, UK. email: k.hussain1@bradford.ac.uk
}

and stable conditions [2, 3]. Without safety control systems such as antilock braking system, a vehicle might become unstable [4] through wheel lock on the front or rear axle and resultant loss of directional control.

During conditions of moderate braking, a vehicle is considered unstable if it deviates from a required straight-line path [5]. The extent of deviation may vary [6], but, however large or small the deviation, it is unacceptable by today's industry standards [7]. Under such deviation, the driver must apply torque to the steering wheel in order to maintain the required straight-line path [8] that creates driver discomfort and subsequently reflects on the driver's perception of the quality of the vehicle [9]. A condition where a vehicle experiences minor deviation from its straight ahead path of travel during braking is termed as 'steering drift' [7], as illustrated in Fig. 1.

Braking forces are transmitted to the vehicle body through the suspension and its linkages [10]; therefore, the design of the suspension must play an important role in ensuring braking stability. Any asymmetry in 


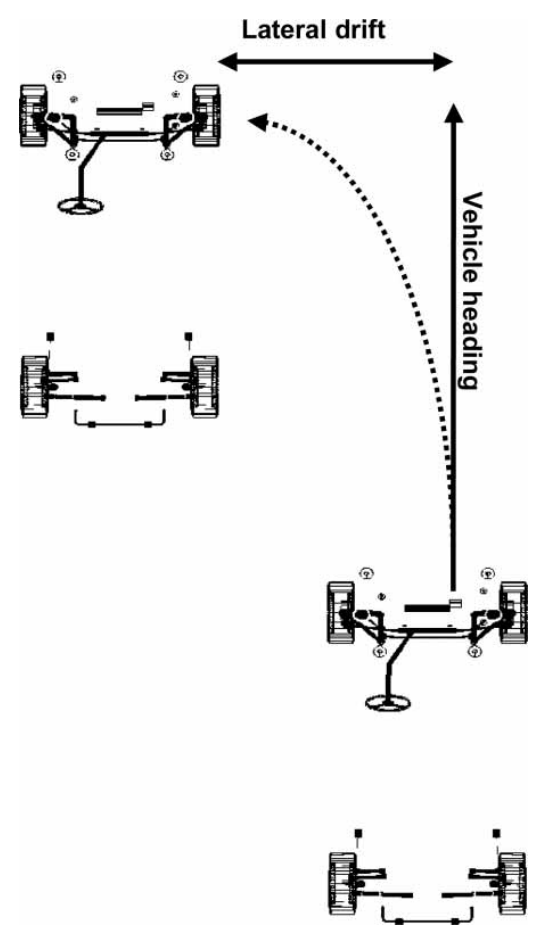

Fig. 1 Vehicle deviating from straight-line path

the suspension layout could result in asymmetrical forces being applied to either side of the vehicle [11]. Braking forces that are dependent on brake system parameters such as coefficient of friction and applied hydraulic line pressure can be different side to side and consequently affect the vehicle during straightline braking [12], although this would be very unusual in modern automotive design. However, even with equal side-to-side braking forces, different side-toside suspension deflections can affect the steered wheel geometry (caster, toe, etc.) and have been shown experimentally to be a key cause of steering drift during braking [13]. Schematics of various vehicle characteristics are shown in Fig. 2.

The approach taken in this article was to investigate vehicle lateral drift during braking by simulation using the automatics dynamics analysis of mechanical system (ADAMS) multi-body dynamics simulation software. The front and rear suspension of the passenger car previously studied experimentally and fully described by the authors $[\mathbf{7}, \mathbf{1 3}]$ was modelled; the front suspension model represented the MacPherson strut design of the vehicle and included a rack and pinion steering system, brake system, engine subframe, and a powertrain unit.

\section{VEHICLE MODEL}

In order to study the effects of the component deflection on vehicle handling during braking, suspension components such as the subframe and the lower control arm were modelled as deformable structures.
These components connect to the vehicle body and suspension through bushing mounts, and can significantly influence vehicle handling as the deflection between these components affects wheel position [7]. By assuming negligible deflection of these components, the overall effect of component deformation on global vehicle behaviour is also neglected $[\mathbf{1 4}, \mathbf{1 5}]$. Figure 3 shows the vehicle model presented in this article comprising of the flexible subframe and lower control arm, and Table 1 shows the suspension alignment data for the vehicle (see reference [7] for parameter definitions).

From Table 1, it can be seen that the front suspension data demonstrated some asymmetry in the suspension alignment. To identify the factors that could affect steering drift, a sensitivity analysis was performed, taking into account the suspension characteristics as well as the effect of compliance and the vehicle attitude. This study has been presented separately $[\mathbf{1 6}, \mathbf{1 7}]$. A summary of the findings of these two papers is given in Table 2.

\section{FULL VEHICLE SIMULATIONS}

The vehicle model was run to simulate a test speed of $100 \mathrm{~km} / \mathrm{h}$ with braking initiated at time $2 \mathrm{~s}$. At $\sim 2.3 \mathrm{~s}$ vehicle deceleration started at a constant rate of $0.7 \mathrm{~g}$, and the simulation continued at this deceleration until $6.2 \mathrm{~s}$ where it came to rest (as seen in Fig. 4). The braking is applied using a braking controller readily available within the ADAMS/Chassis module. A proportional integral derivative (PID) control strategy was used that calculates the required braking torques on each wheel to achieve the desired deceleration. The required inputs for the controller are brakes on time and brakes off time (ramp time), braking history spline (time versus required deceleration), and braking proportion spline (front to rear split, in this case 80/20). In our study, the vehicle was driven at a constant velocity of $100 \mathrm{~km} / \mathrm{h}$ for $2 \mathrm{~s}$. After $2 \mathrm{~s}$ the controller was triggered on to check the required deceleration rate (in our case $0.7 \mathrm{~g}$ ). A ramp time of $0.5 \mathrm{~s}$ is used by the controller to steadily increase the force on the wheels, using the $80 / 20$ split, until the desired deceleration is achieved. Once this has been achieved, it was maintained at this value.

The simulation was run under two conditions of driver steering input: fixed and free control. In 'fixed control' the steering wheel was held at a constant angle of zero from the time the brakes were applied until the vehicle came to rest. Here the steering wheel torque was therefore non-zero. In 'free control' the steering wheel torque was maintained at a constant zero value, thereby resulting in a non-zero steering wheel angle. Comparison of the results showed that the full vehicle simulations with flexible bodies did not predict any difference in vehicle lateral reactions between the 


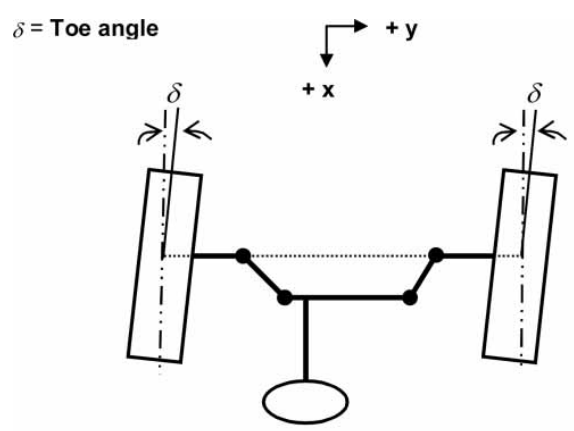

(a)

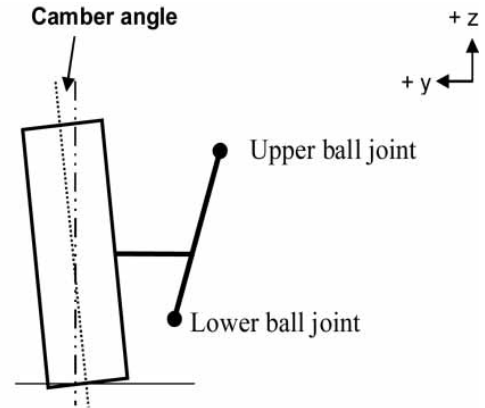

(b)

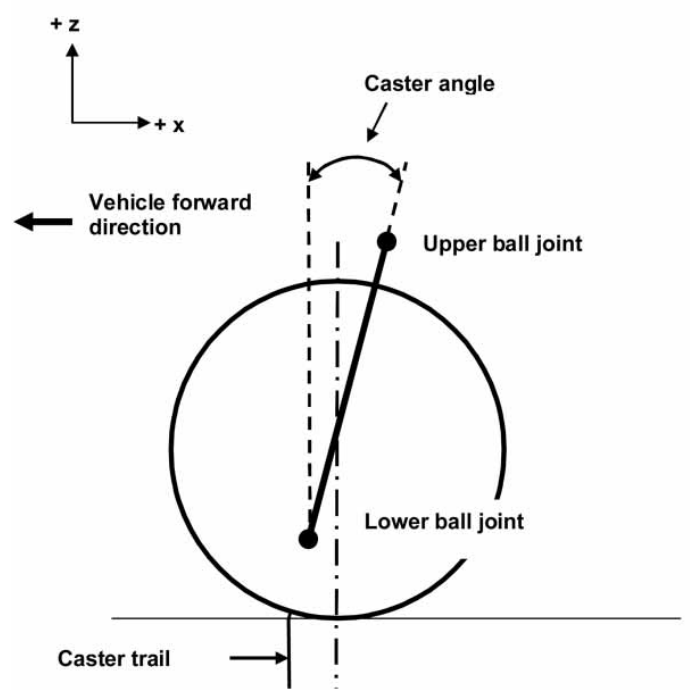

(c)

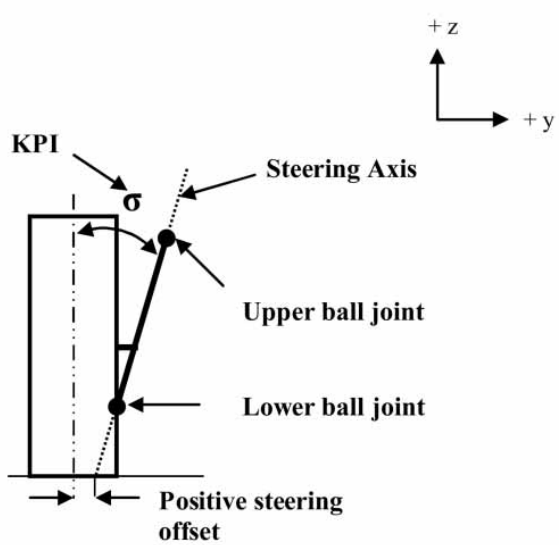

(d)

Fig. 2 (a) Toe steer angle, (b) camber angle, (c) caster angle, and (d) kinpin inclination and steering axis

two methods. Therefore, the results and discussions presented in this article refer to the 'fixed control' method. Previous experimental work by the authors

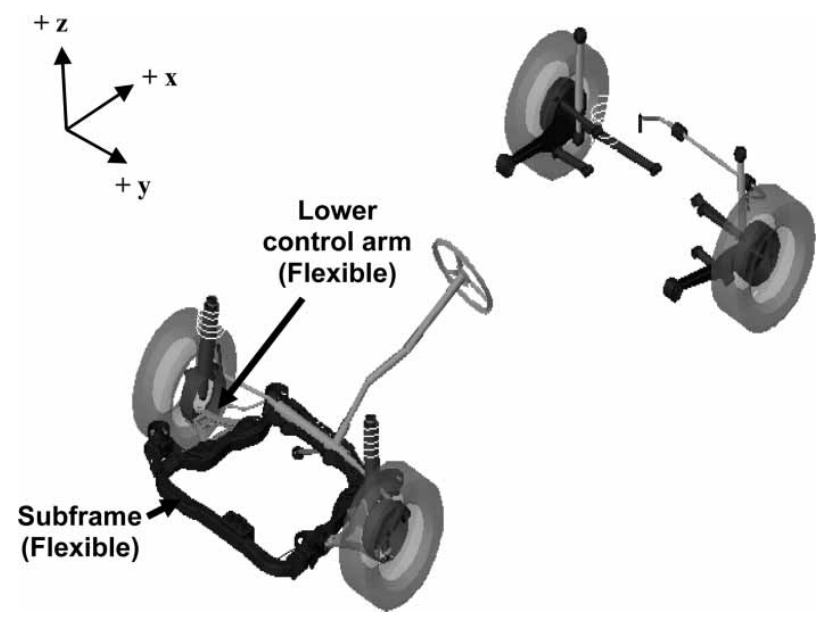

Fig. 3 Full vehicle model with flexible subframe and lower control arm
$[7,13]$ had indicated that this was fully compatible with the experimental findings provided that the predicted results were compared with the measured data for 'fixed control'.

\section{VEHICLE LATERAL REACTION DURING STRAIGHT-LINE BRAKING}

Figures 5(a) and (b) show predicted results for lateral acceleration and yaw velocity for the simulated vehicle. The test vehicle and instrumentation were fully described by the authors in two previous papers [7, 13] . In both cases, the results were compared against the measured data [13], and it can be seen from Figs 5(a) and (b) that as the brakes were applied, lateral acceleration and yaw velocity steadily increased with a positive value indicating steering towards the left (it should be noted that the lateral acceleration time history plot has been inversed for comparison with measured data). In both cases, the measured values for lateral acceleration and yaw velocity were slightly 
Table 1 Suspension alignment data

\begin{tabular}{lccccc}
\hline \multicolumn{5}{c}{ Suspension geometry and alignment } \\
\cline { 2 - 3 } & \multicolumn{2}{c}{ Instrumented vehicle } & & \multicolumn{2}{c}{ ADAMS model } \\
\cline { 2 - 3 } \cline { 5 - 6 } & Left & Right & & Left & Right \\
\hline Front suspension & & & & 0 \\
Toe angle $\left(^{\circ}\right)$ & -0.167 & -0.167 & & 0 & 0.999 \\
Camber angle $\left(^{\circ}\right)$ & -0.33 & 1.0 & & -0.33 & -0.16 \\
Kingpin angle $\left(^{\circ}\right)$ & 13.83 & 14.16 & & 13.6 & 14.16 \\
Caster angle $\left(^{\circ}\right)$ & 2.16 & 2.33 & & 2.17 & 2.34 \\
Rear suspension & & & & 0 \\
Toe angle $\left(^{\circ}\right)$ & 0 & 0.166 & & 0.833 & 0 \\
Camber angle $\left(^{\circ}\right)$ & -0.833 & 0 & & -0.17 \\
\hline
\end{tabular}

Table 2 Summary of sensitivity analysis

\begin{tabular}{ll}
\hline Single factor & Effect \\
\hline $\begin{array}{l}\text { LCA rear bushing stiffness radial } Y \\
\text { direction }\end{array}$ & $\begin{array}{c}\text { Most significant } \\
\text { factor } \\
\text { Effect } \\
\text { Interactions }\end{array}$ \\
$\begin{array}{l}\text { Top mount hard point location } Y \\
\text { direction/LCA rear bushing stiffness }\end{array}$ & $\begin{array}{l}\text { interaction term } \\
\text { radial } Y \text { direction }\end{array}$ \\
$\begin{array}{l}\text { Top mount hard point location } Y \\
\text { direction/LCA front bushing stiffness }\end{array}$ & $\begin{array}{c}\text { Second most } \\
\text { significant }\end{array}$ \\
radial $Y$ direction & interaction term \\
location)/LCA rear bushing stiffness & Minor effect \\
radial $Y$ direction & \\
\hline
\end{tabular}

greater in magnitude than the predictions. The predicted results show lateral acceleration to a peak of $0.89 \mathrm{~m} / \mathrm{s}^{2}$, whereas in the measured data, lateral acceleration peaks at $1 \mathrm{~m} / \mathrm{s}^{2}$. The predicted yaw velocity peaks at a maximum value of $2.7^{\circ} / \mathrm{s}$, whereas the measured yaw velocity peaks at $3 \%$ s. However, in both cases it is observed that the measured and predicted results show similar trends.

Figure 5(c) shows the predicted lateral displacement of the vehicle during braking. The magnitude of displacement was $2.3 \mathrm{~m}$ for the simulated model, and when compared with the test vehicle a difference of
$0.56 \mathrm{~m}$ was observed (maximum lateral displacement was measured at $2.8 \mathrm{~m}$ [13]), i.e. the test vehicle experienced more drift than the simulation predicted (full time history data for lateral displacement of the test vehicle were not available). From Figs 5(a) to (c), it can be concluded that the test vehicle showed more lateral drift than the simulated model. This difference between the lateral displacement, acceleration, and yaw velocities can be clearly observed from the steering wheel torques shown in Fig. 6.

Figure 6 shows the steering wheel torques for predicted and measured data. Here steering to the left is indicated by a positive value of steering wheel torque. As the brakes were applied, in both cases the vehicle steered to the left. A comparison between predicted and measured results at this point indicates that in both cases the vehicle steered to the left, and the measured magnitude of steering wheel torque was $1.3 \mathrm{Nm}$ compared with the predicted value of $1 \mathrm{Nm}$. Therefore, it can be concluded that the test vehicle steered to the left more than the simulation predicted, and a difference in the magnitudes of lateral displacement, acceleration, and yaw velocity was observed.

\section{SUSPENSION CHARACTERISTICS}

The predicted front left and right toe steer angles are shown in Fig. 7, from which it can be observed that at the moment of brake application the right wheel momentarily toed-in while the left wheel toed-out (at time $2 \mathrm{~s}$ ), indicating that the wheels were oriented towards the left. This corresponds with the predicted steering wheel torque that shows a positive value indicating steering to the left (see Fig. 8). As the vehicle decelerated, the wheels began to change their orientation, the right wheel toed-out and the left wheel toed-in (also indicating wheels oriented towards the right), reaching a peak value at time $2.5 \mathrm{~s}$. At this moment, the predicted steering wheel torque in Fig. 8

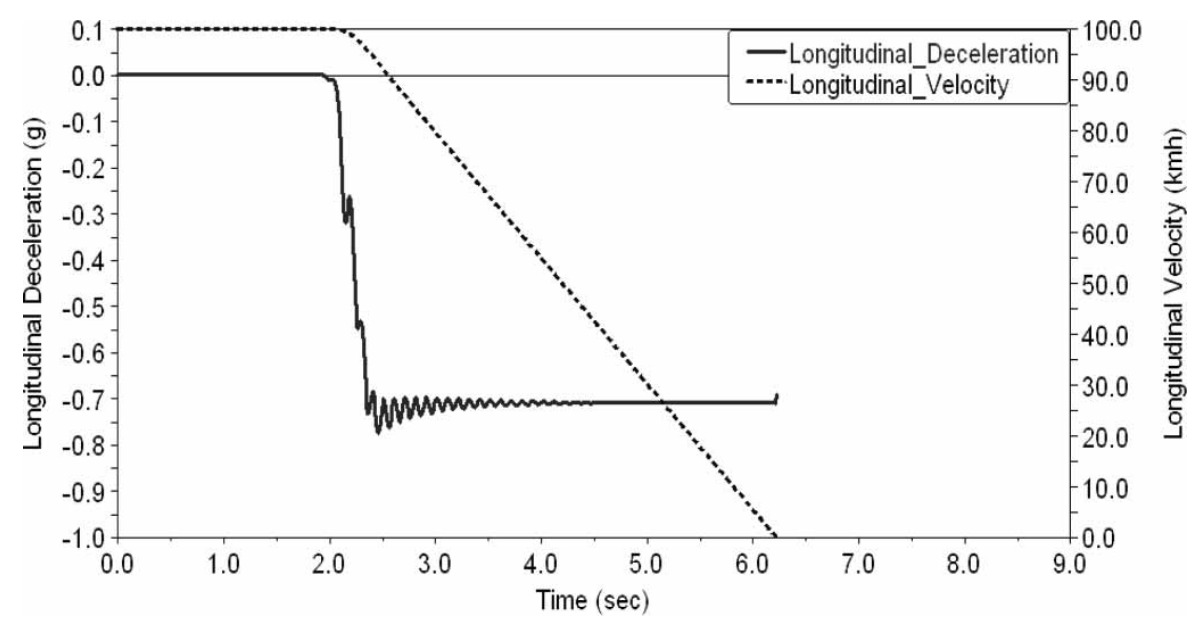

Fig. 4 Longitudinal velocity and deceleration rate 


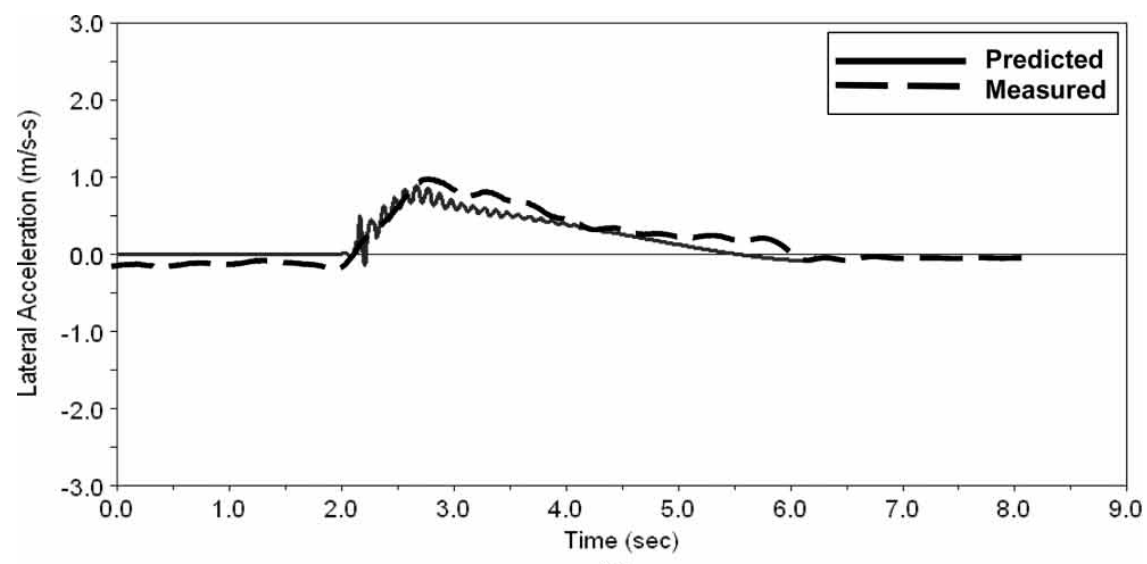

(a)

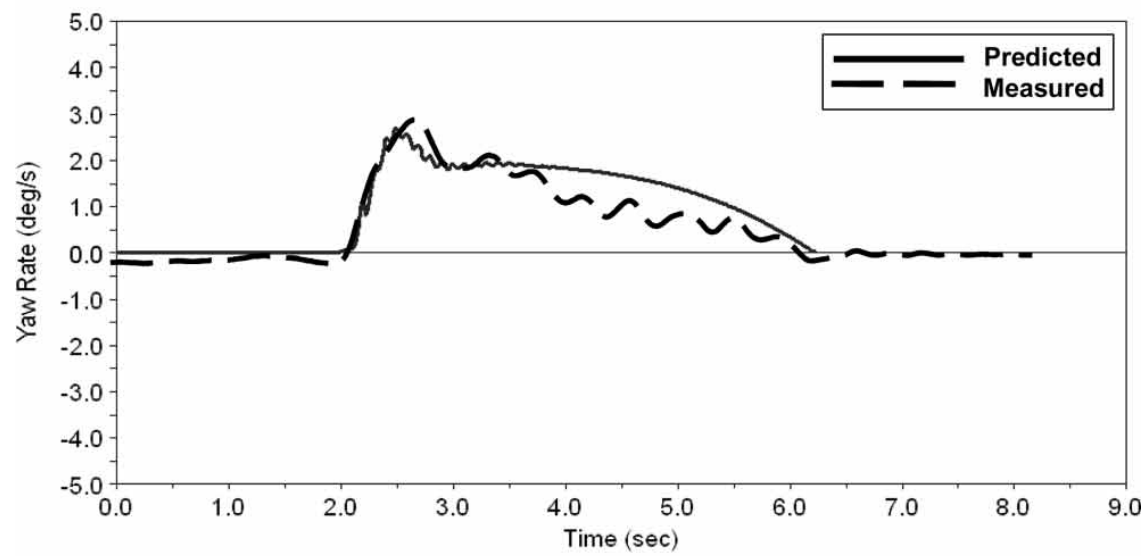

(b)

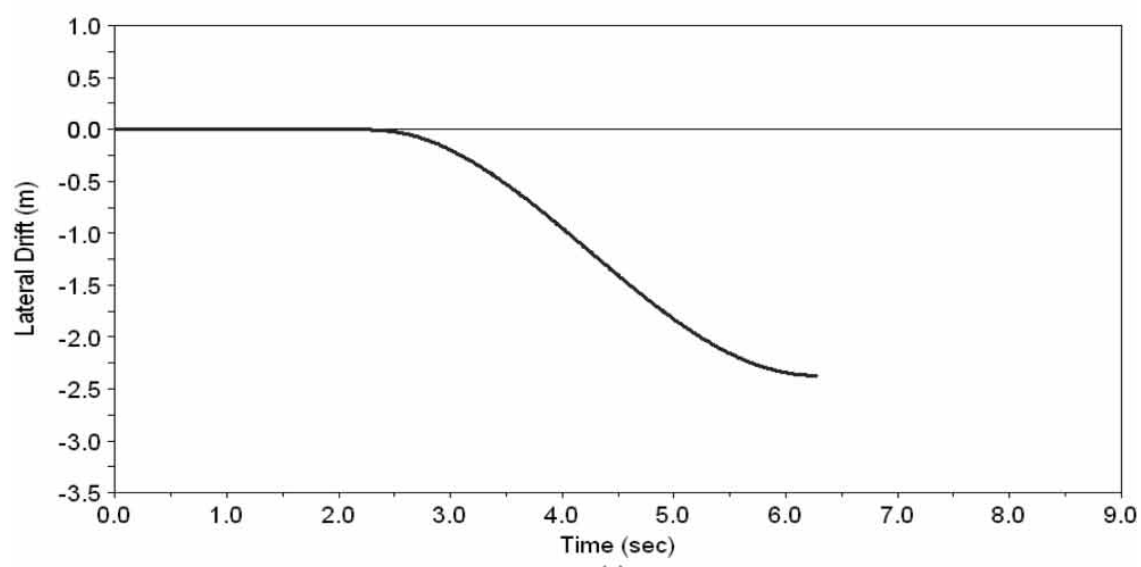

(c)

Fig. 5 (a) Lateral acceleration, (b) yaw velocity, and (c) lateral displacement of the simulated vehicle: predicted and measured

shows a negative value indicating steering to the right. The time-dependent change in wheel orientation that was predicted and measured is possibly due to the dynamic response of the vehicle and visco-elastic effects in the subframe mounts and tyres.

After time $2.5 \mathrm{~s}$, the wheels began to change orientation; the toe angle on the front right wheel reduced and changed to toe-in, while the left wheel changed to toe-out. During this time period the steering wheel torque showed a change from a negative value to a positive value (indicating that the vehicle began to steer to the left). Figure 8 shows a relationship between toe steer angles and steering wheel torque (predicted results of Figs 6 and 7), indicating that the steering system could have an influence on steering drift during braking.

The toe variation seen in Fig. 7 could originate from the influence of the steering system or 


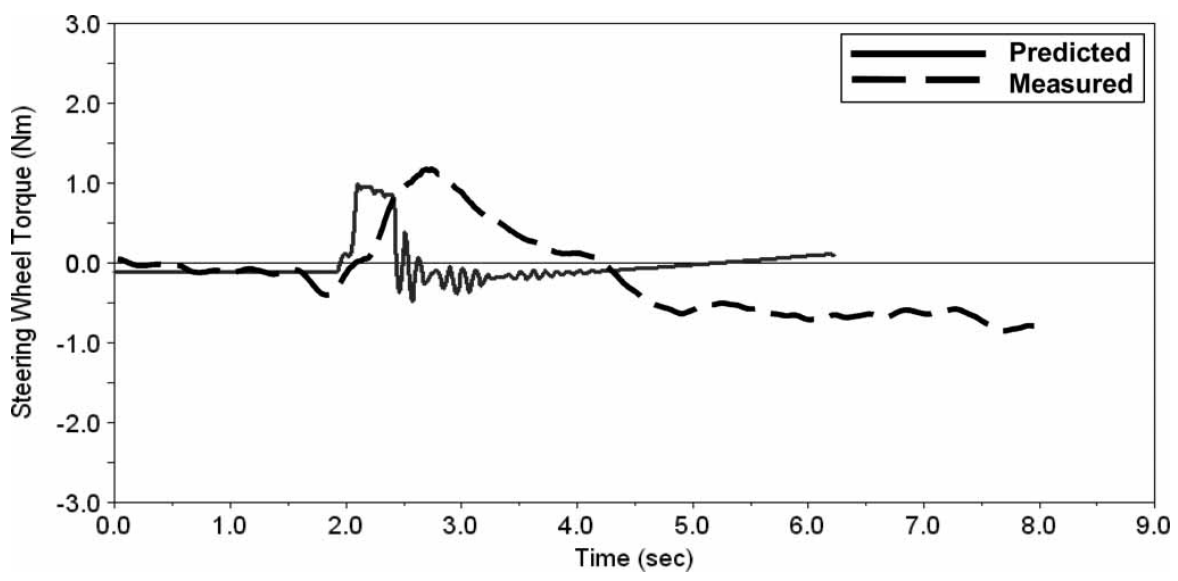

Fig. 6 Steering wheel torque: predicted and measured

the front wheels could cause these changes. Therefore to identify the system, the following forces and moments generated within the suspension were analysed: (a) moment about the kingpin axis due to braking forces (kingpin or steering axis is the axis about which the wheels pivot when steered);

(b) tie rod forces.

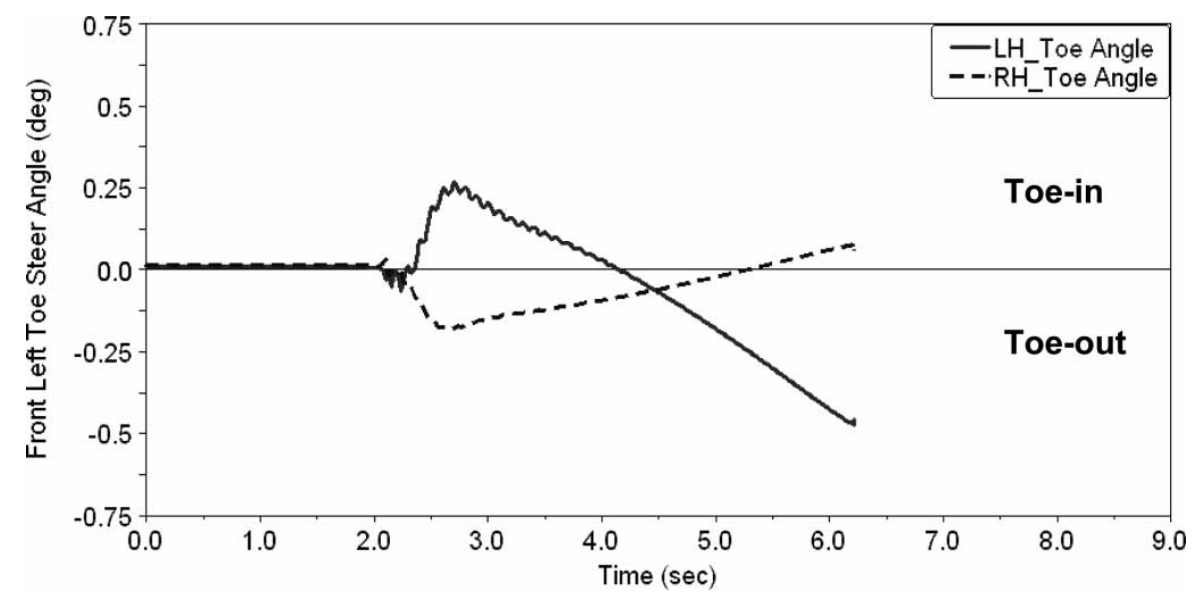

Fig. 7 Toe steer angle $\left(^{\circ}\right)$

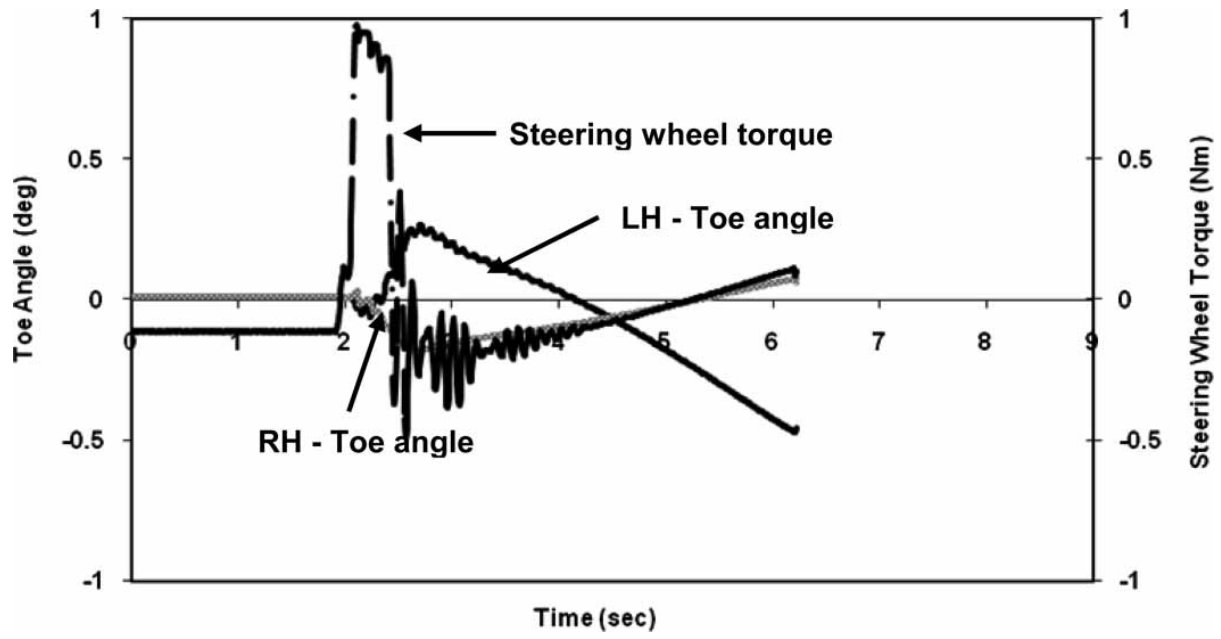

Fig. 8 Comparison of toe steer angle and steering wheel torque 
Figure 9 shows the moment generated around the steering axis due to the braking forces. The moment generated about the steering axis is given by equation (2) and is dependent on the steering offset (scrub radius), kingpin inclination (KPI) angle, caster angle, and braking force [18]. The nature of this moment is such that it causes the wheel to toe-in during braking if the steering offset is negative. Therefore, a positive value of this moment would cause toe-in and a negative value would cause toe-out

$$
\begin{aligned}
& R_{\mathrm{b}}=r_{\mathrm{s}} \cos (\alpha) \\
& M_{\mathrm{SA}}=F_{\mathrm{B}} \cos (\delta) r_{\mathrm{b}}
\end{aligned}
$$

From Fig. 9 it is seen that the left wheel experienced a positive moment that caused the wheel to toe-in. This moment changed to a negative value at $2.5 \mathrm{~s}$ into the simulation that would cause wheel toe-out. This corresponded to the behaviour of the front left wheel as seen in Fig. 7. However, this was not the case for the right wheel. After $1 \mathrm{~s}$ from the point of application of the brakes the right wheel toed out, and at this point the moment about the steering axis had a positive value (on the right-hand side, as seen in Fig. 9). Therefore, the right wheel toe angle negated the applied moment. As the vehicle decelerated, the moment reduced rapidly (negative value) and then increased from time $2.6 \mathrm{~s}$, returning to a positive value. At this point the right wheel began to toe-in, which corresponded to the steering axis moment (from time $2.6 \mathrm{~s}$ onwards). Therefore, it can be said that the steering axis moment partially defines toe steer angle.

The difference in steering axis moment between the left and right wheels can be further explained from the time history plots for steering offset, KPI, and caster angle. Under static conditions caster angle was predicted to be 2.16 and $2.33^{\circ}$ on the left and right sides of the front suspension, respectively. During constant deceleration, the predicted caster angle increased to $\sim 3^{\circ}$, mainly due to the strut assembly being pulled back during forward motion. In Fig. 10, on the brake

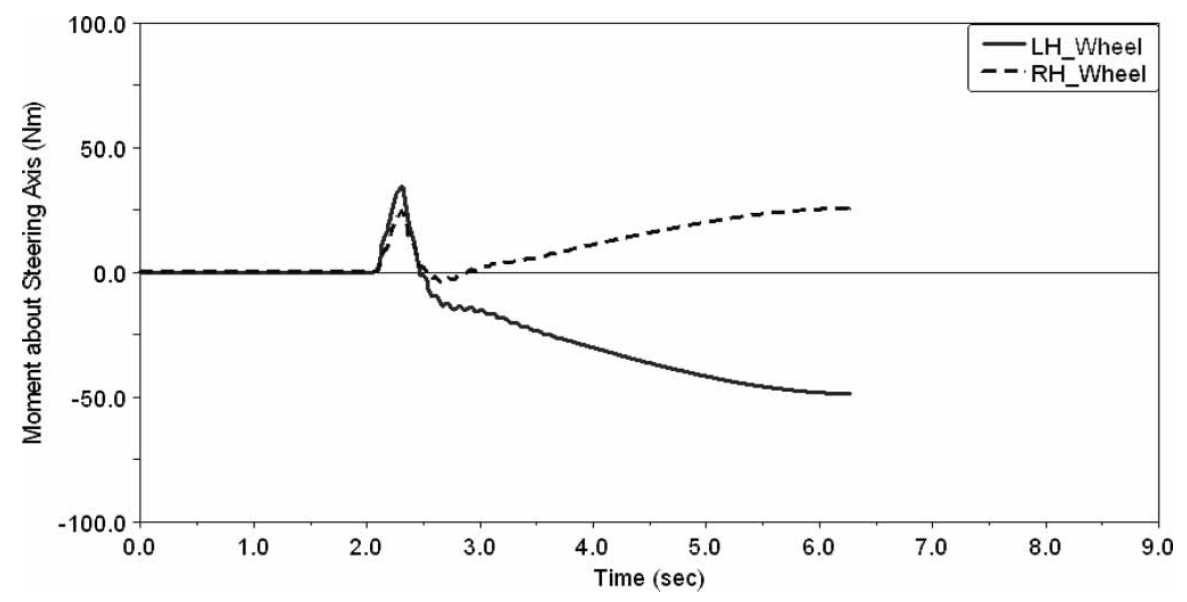

Fig. 9 Moment about the steering axis (Nm)

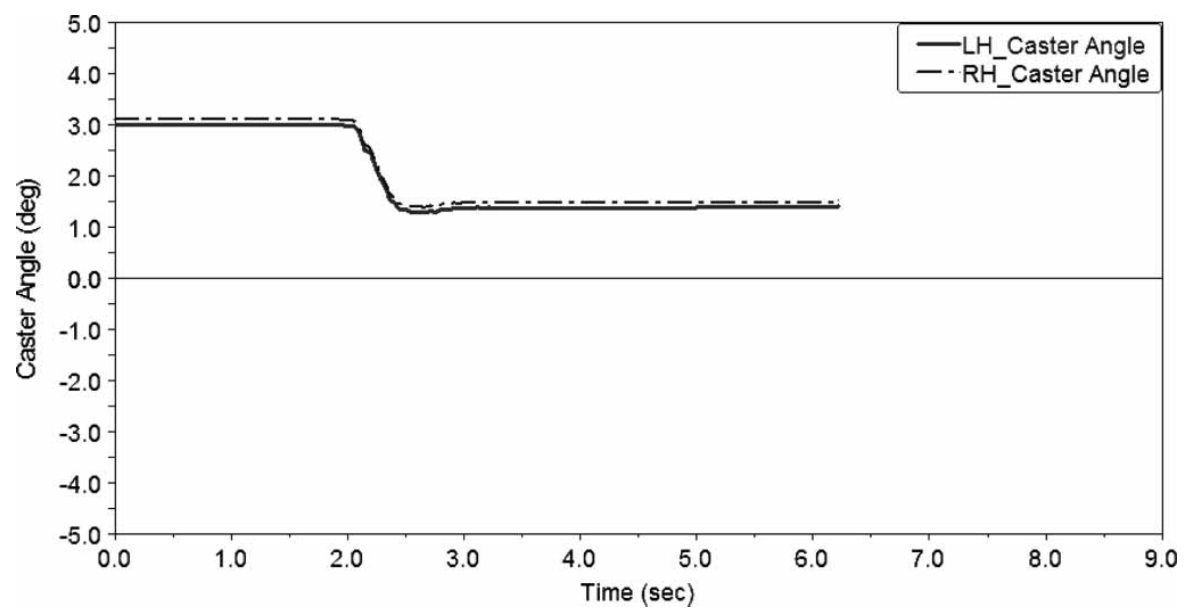

Fig. 10 Caster angle $\left(^{\circ}\right)$ 
application, predicted caster angle reduced (on both left and right sides) as a result of suspension compression. It then reached a steady-state value of $1.5^{\circ}$. The difference between the left and right was negligible; therefore, the influence of caster on steering axis moment must also be negligible.

Figure 10 illustrates the steering offset; the static value was set at $-6.5 \mathrm{~mm}$ (outboard), but under dynamic conditions this increased to $-7 \mathrm{~mm}$. At the point of application of the brakes, the predicted steering offset on both wheels increased until time $2.5 \mathrm{~s}$ after which the right steering offset decreased whereas on the left it increased. From equation (2), it is known that brake force moment arm $\left(r_{\mathrm{b}}-\right.$ the product of steering offset and KPI) directly influences steering axis moment; therefore, an increasing value of steering offset would increase the positive moment and a decreasing value would decrease the positive moment.

Referring to Figs 9 and 11, it can be observed that the predicted left steering offset increased. This increase should also increase the positive moment at the left wheel (keeping the wheel to toe-in). This was observed up to time $2.3 \mathrm{~s}$, after which the steering axis moment decreased in spite of an increase in steering offset; the negative value of the moment encouraged the wheel to toe-out. Similarly, on the right side, steering offset decreased (after time $2.5 \mathrm{~s}$ ), which should result in a much smaller moment, but it increased up to $\sim 50 \mathrm{Nm}$, which was the same as the value between time 2 and $2.5 \mathrm{~s}$ when the steering offset on the right was increasing during the initial period of braking.

The resulting steering axis moment does show similarities between left and right (on the right only after $2.6 \mathrm{~s}$ ) predicted toe steer angle; however, it did not comply with the changes occurring in steering offset. Therefore, the moment appears not to have an influence on toe steer angle, it merely reflects the orientation of the wheels as the vehicle decelerates.
Since steering offset is a function of KPI, this is also examined. KPI is defined in terms of the lateral position of the lower ball joint and the strut top, and this reflects the effect of deflections in these two positions on the instantaneous suspension characteristics. Any change in steering offset indicates a change in KPI angle or track (the lateral distance between the two wheel centres on an axle). An increasing value of KPI would increase the lateral distance between the wheel centre and the intersection of the steering axis at the road surface; in other words, it would increase the steering offset (scrub radius). A change in KPI would occur if there were lateral deflection of the strut top or the lower ball joint. If KPI remained unchanged and the wheel experienced lateral deflection, this would result in a reduction in steering offset. But if a change in KPI and lateral wheel deflection (increase or decrease) were to occur simultaneously, this would result in more or less equal increase or decrease in steering offset.

Figures 12(a) and (b) show the predicted lateral deflection of the strut top and the lower ball joint. From Fig. 12(a) it can be observed that there was negligible lateral deflection of the strut between the left and the right. However, this was not the case for the lower ball joint. Figure 12(b) shows that the ball joint was predicted to deflect in the outward direction on both sides, where deflection towards the left is negative and deflection towards the right is positive.

Figure 12(b) clearly indicates that the right lower ball joint was predicted to deflect more than the left, therefore indicating an increase in KPI and hence an increase in steering offset on the right (between time 2 and 2.5 s). This can be observed in Fig. 11 at 2.5 s; after this point in the simulation, predicted steering offset decreased as a result of a decrease in ball joint deflection (on the right) (see Fig. 12(b) after time $2.5 \mathrm{~s}$ ). On the left side the ball joint deflected along the negative $y$-axis, this deflection continued to increase until

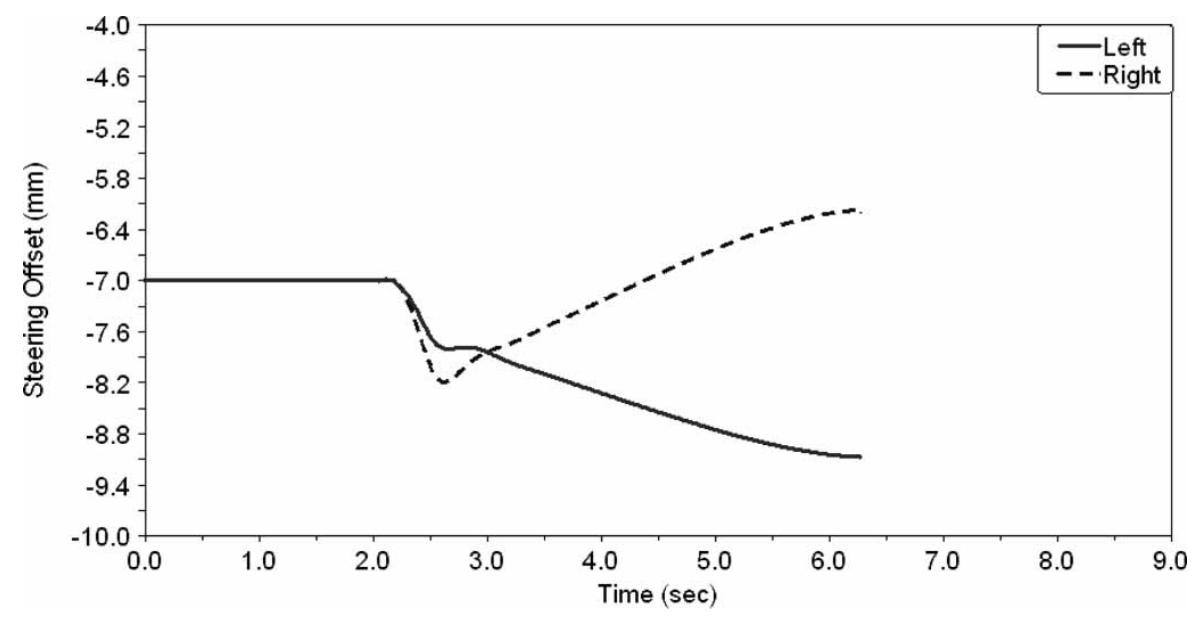

Fig. 11 Steering offset on the front left and right wheels (mm) 
the vehicle came to rest; this is reflected in the steering offset that was predicted to continue to increase until $6.2 \mathrm{~s}$.

The wheels deflected along the $y$-axis in a manner similar to the lower ball joints during braking (see
Fig. 12(c)); therefore, suspension compression results in an increase in track width. The magnitude of deflection of the wheels was the same as that of the lower ball joints; hence, there was no additional effect on steering offset.

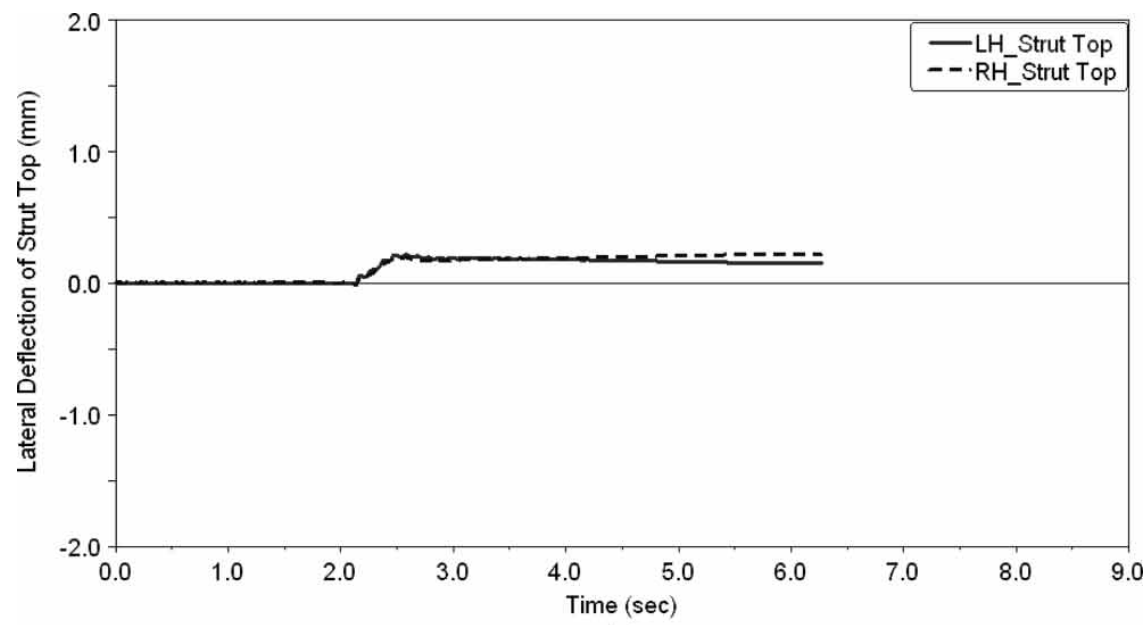

(a)

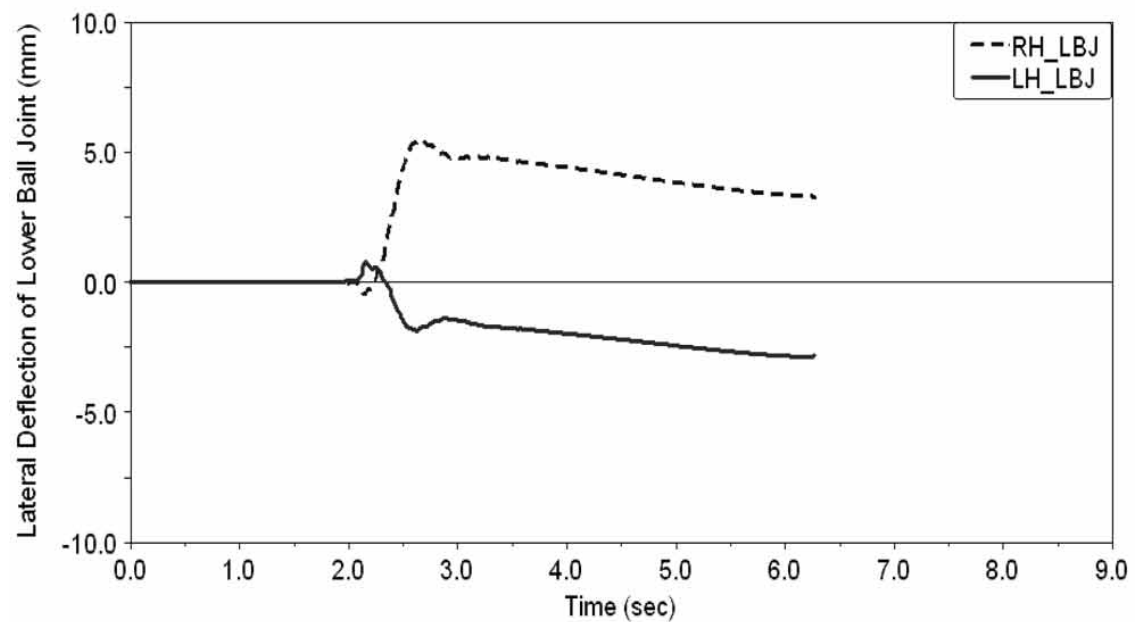

(b)

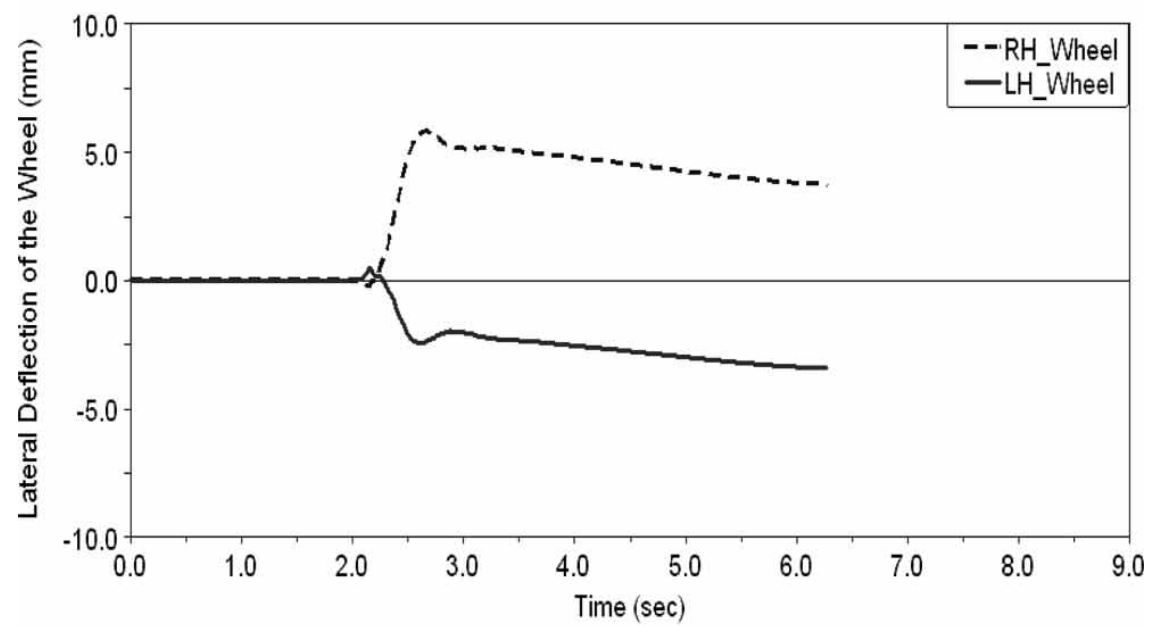

(c)

Fig. 12 (a) Lateral deflection of the strut top, (b) lower ball joint, and (c) lateral deflection of the front wheels 
For the steering axis moment, it was observed that the left wheel movement complied with the applied moment, whereas the right wheel corresponded only from $2.6 \mathrm{~s}$ onwards. A direct influence of steering axis moment on toe angle could not be identified at this point. However, the steering axis moment does highlight the sensitivity of the front wheels to braking forces, KPI (lower control arm deflection) and steering offset.

\section{FORCES GENERATED IN THE TIE RODS DURING BRAKING}

The moment created about the steering axis generates (dependent on the suspension characteristics) a force in the tie rods, which in turn affects toe steer angle and subsequently, if different from side to side, this force can influence directional stability during braking by creating small angle changes in the wheel toe [19]. By examining the tie rod force, it can be confirmed if the front wheels are acting or reacting with respect to toe steer angle.

Under typical driving conditions toe steer angles should correspond to the steering wheel angle [13]. Since the simulation was performed under fixed control, steering wheel angle was held fixed at a constant value of zero degrees. Hence, toe steer angle would not correspond to steering wheel angle. To analyse the behaviour of toe steer angle, the forces induced by the steering rack on the tie rods were analysed. In order to confirm that the wheel itself did not influence toe steer angle, tie rod forces were predicted for two locations (see Fig. 13 for steering gear and tie rod assembly):

(a) steering arm force on the tie rod;

(b) steering rack force on the tie rod.

The reason for the prediction from two locations was to identify the point of origin for the tie rod forces. If

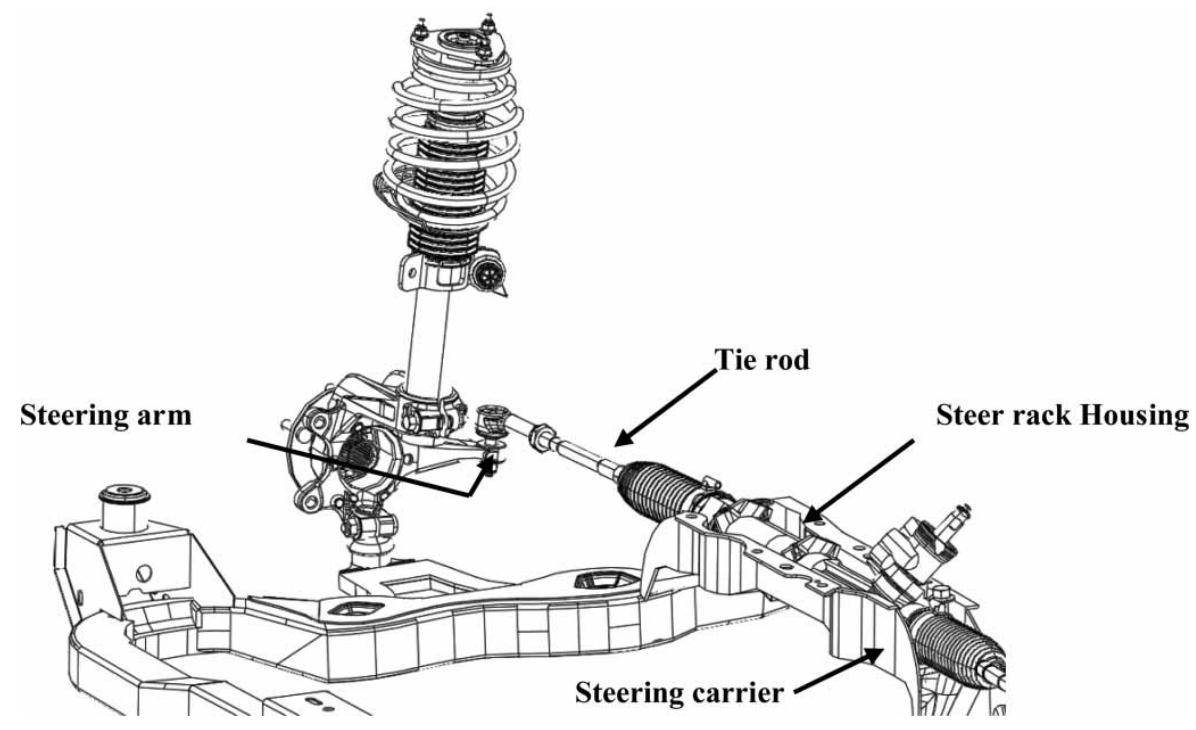

Fig. 13 Steer gear and tie rod assembly

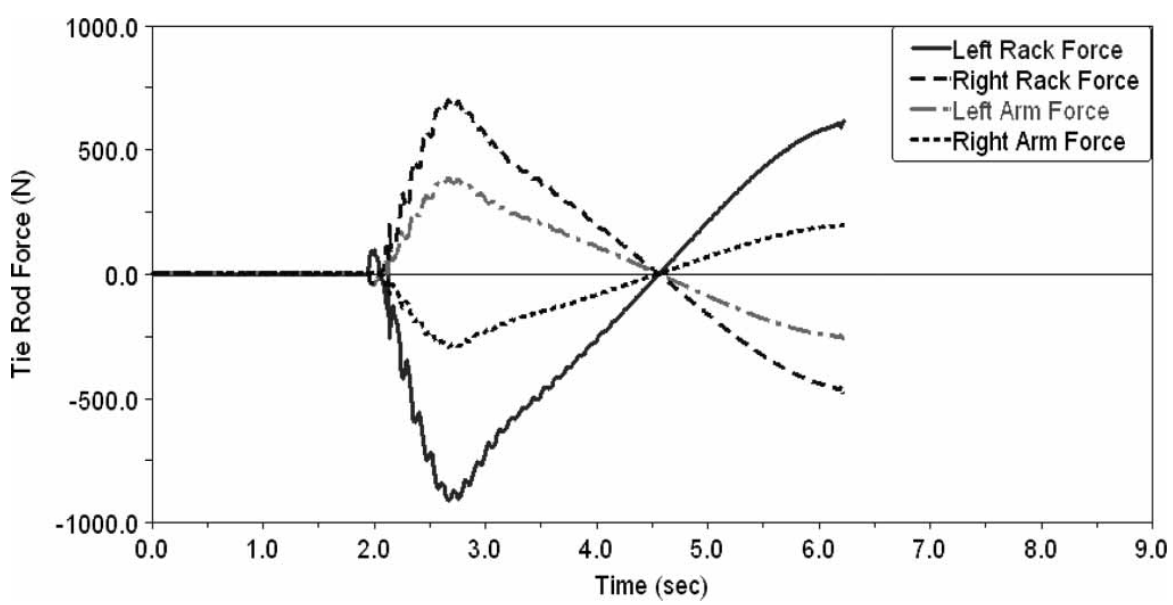

Fig. 14 Steering arm and steering rack forces on tie rods (N) 
the steering arm was applying a force on the tie rod then:

(a) push forces are indicated by a positive value;

(b) pull forces are indicated by a negative value.

The opposite sign convention applies for the steering rack force on the tie rod:

(a) push forces are indicated by a negative value;

(b) pull forces are indicated by a positive value.

Figure 14 shows the predicted forces induced by the steering arm and the steering rack on the tie rods. Here it can be clearly seen that the left steering arm force (indicated by a dotted and dashed line) pushed the tie rod towards the rack (indicated by a positive value). However, the left side of the rack exerted a much higher force on the tie rod pushing it towards the steering arm (indicated by a negative value). A similar explanation can be given for the forces on the right side. Figure 14 clearly indicates that higher force was exerted by the steering rack on the tie rods, which could influence the front wheels.

A comparison between toe steer angles and tie rod forces is shown in Fig. 15. Tie rod forces shown in this figure refer to those induced by the steering rack. It is observed that at the moment of the application of brakes the left tie rod exhibited a negative force and the right tie rod exhibited a positive force, indicating a push and pull force exerted by the rack on the left and right tie rods, respectively. This is confirmed by Figs 7 and 8 where the front wheels show toe-out and toe-in on the left and right wheels, respectively, along with steering to the left indicated by steering wheel torque.

As the vehicle decelerated, a push force was generated on the left steering arm that might cause the wheel to toe-in, whereas the right tie rod pulled the steering arm (right), implying that the right wheel would toe-out. This is confirmed from Fig. 7, which shows the front left wheel in toe-in and the right in toeout. After $2.7 \mathrm{~s}$ the tie rod forces reduced and changed sign, the left tie rod exerted a pull force and the right exerted a push force. This again corresponds with the movement of the front wheels that show a change in toe after $2.5 \mathrm{~s}$.

In addition to the tie rod forces, the movement of the tie rods, steering carrier, and steering rack were also predicted. The tie rods are connected to the steering gear that is housed on the steering carrier, which is connected to the subframe. Therefore, deflections generated by the subframe would be transmitted via the carrier through the rack and to the tie rods.

Figures 16(a) and (b) show the lateral deflections of the carrier and tie rods. Referring to Fig. 16(a), at the point of braking the left side of the steering carrier predicted positive lateral deflection between 2 and $2.2 \mathrm{~s}$. This deflection suggests movement along the positive $y$-axis. After $2.2 \mathrm{~s}$ negative deflection is observed (on the left), which reaches a maximum of $0.13 \mathrm{~mm}$ at $2.6 \mathrm{~s}$. After this point the lateral deflection on the left approaches zero and changes to a positive value until the vehicle came to a halt. The right side of the carrier shows a steadily increasing deflection (negative) reaching its peak at $2.6 \mathrm{~s}$; deflection predicted at this point is $0.28 \mathrm{~mm}$ after which the deflection on the right decreases and changes to a positive value at $5.25 \mathrm{~s}$.

Since the steering rack is housed on the steering carrier, the deflection of the carrier would generate movements within the rack, which may affect the tie rods and may cause changes in toe steer angle on the front left and right wheels. The predictions for the lateral deflections of the steering rack and the tie rods were identical, as shown in Fig. 16(b).

Figure 16(b) shows that the left and right tie rods initially moved along the positive $y$-axis. This movement indicates that there would be a slight toe-out on the left wheel and toe-in on the right wheel. Referring back to Fig. 7, this argument can be confirmed where the front

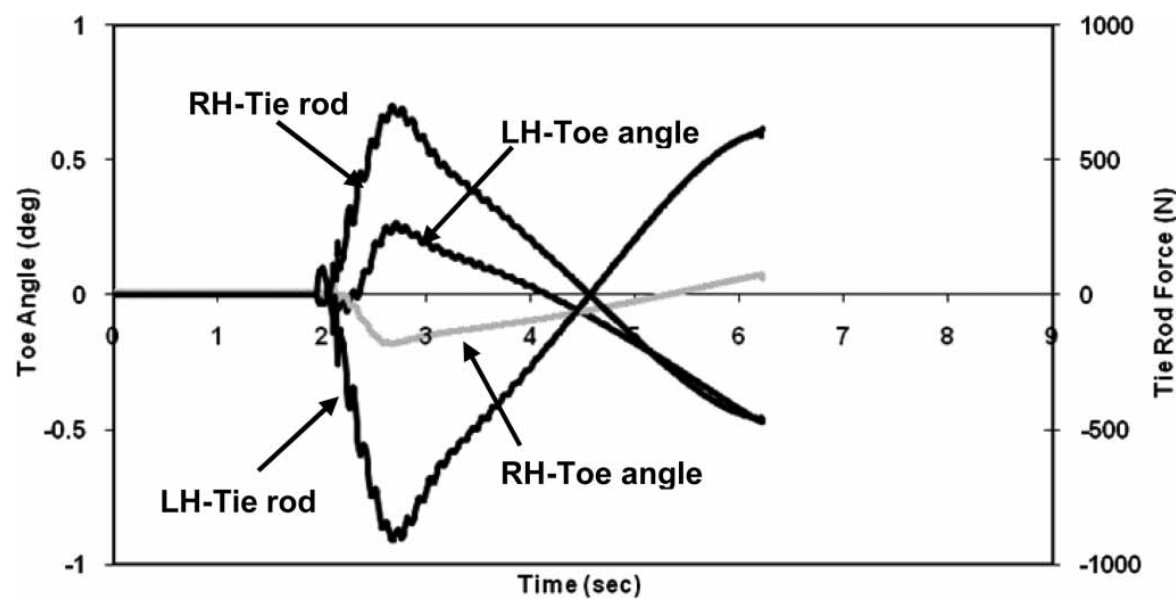

Fig. 15 Comparison between toe steer angle and tie rod force 
left wheel shows a slight toe-out and front right wheels shows a slight toe-in between time 2 and $2.2 \mathrm{~s}$. This can be further explained by the individual tie rod forces as seen in Fig. 17. The initial deflection observed for the left side of the carrier in Fig. 16(a) is along the positive $y$-axis; the effect of this movement implies that the steering rack would move along the same direction (as seen in Fig. 16(b)). Therefore, the rack would apply a pull force on the left tie rod. The pull force applied on the tie rod would indicate tension in the rod, as seen in Fig. 17 between time 2 and $2.2 \mathrm{~s}$. Here tensile force is indicated by a positive sign.

In terms of toe steer angle, the pull force would cause the tie rods to create a slight toe-out on the front left wheel. This argument is confirmed by observing the front left wheel toe steer angle between time 2 and $2.2 \mathrm{~s}$ in Fig. 7. After time $2.2 \mathrm{~s}$ the left side of the carrier deflected along the negative $y$-axis (similar behaviour is seen for the left side of the steering rack (see Fig. 16(b))) indicating a push force that would be applied to the tie rods. The negative force implies compression in the left tie rod, as seen in Fig. 16. This would therefore cause the tie rods to deflect in a similar manner (see Fig. 16(b)), and create toe-in at the front left wheel, as observed from Fig. 7.

On the right side, similar behaviour is seen except that the predicted negative deflection on the carrier steadily increased up to $2.6 \mathrm{~s}$ as seen in Fig. 16(a). For the steering rack (right) a different behaviour can be observed where the rack was displaced initially along the positive $y$-axis and then along the negative $y$ axis. The difference in behaviour between the steering rack and carrier is because the steering rack is a rigid body (unlike the carrier, which is flexible and is integral with the subframe); therefore, it displays identical movement on both sides. However this is only true between time 2 and $2.2 \mathrm{~s}$, after which the rack displays movement similar to the steering carrier.

The steering carrier (right) moved along the negative $y$-axis such that the rack applied a pull force on the tie rod (positive force, see Fig. 17) causing toe-out on the front right wheel. After time $2.6 \mathrm{~s}$ predicted deflection

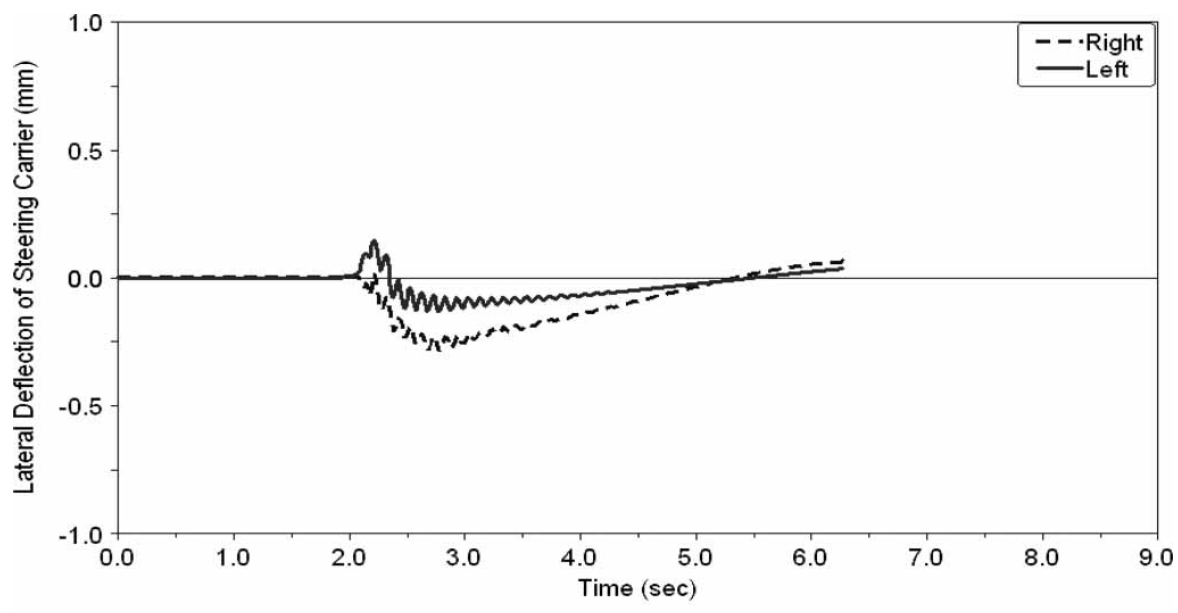

(a)

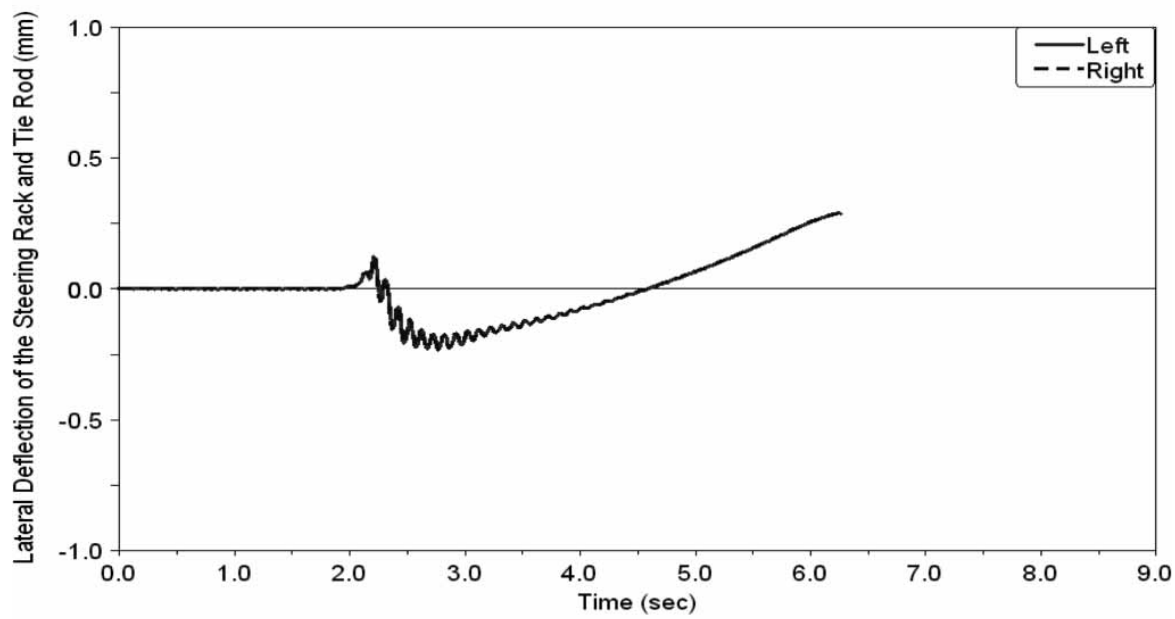

(b)

Fig. 16 (a) Lateral deflection of the steering carrier and (b) lateral deflection of the steering rack and tie rods 


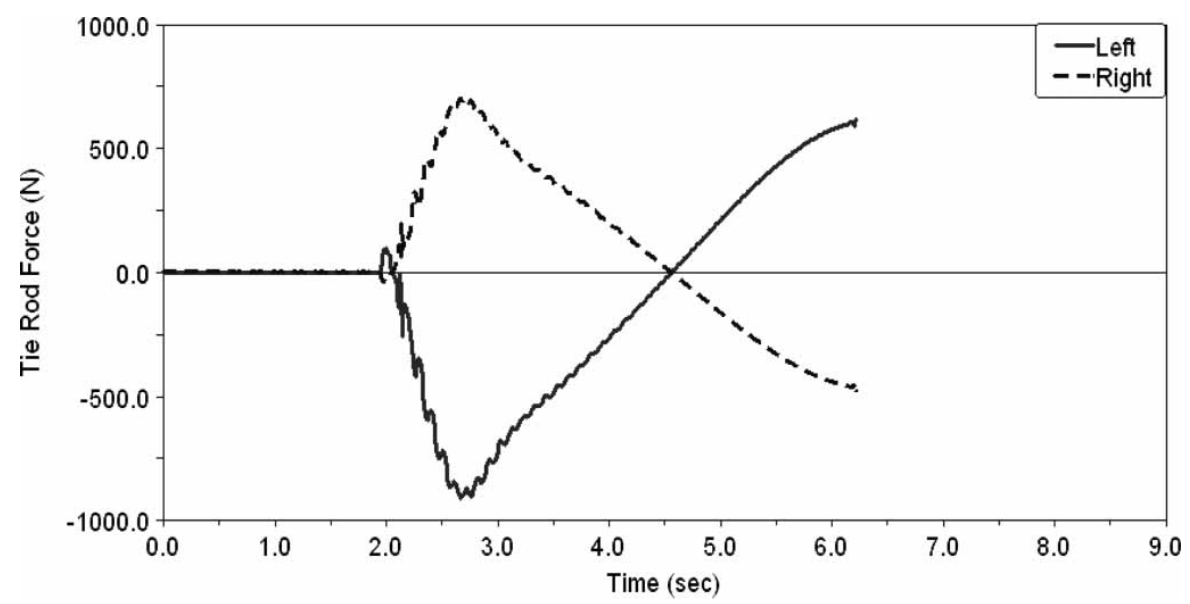

Fig. 17 Tie rod forces with respect to steering rack (N)

decreased (see Fig. 16(a) for the right carrier deflection), and the carrier movement influenced the rack such that it applied a push force on the tie-rods (compression) causing the front right wheel to toe-in (see Fig. 7 for right wheel toe steer angles).

The subframe and the lower control arms used in this investigation were flexible (deformable) components. The movements of the subframe, i.e. the lateral deflections, could generate movements within the suspension assembly. The steering rack and tie rods are housed on the steering carrier (see Fig. 13). Since the carrier is integral with the subframe, any movement, in this case the lateral deflections of the subframe, could directly influence and generate movements within the steering linkages. Figures 16(a) and (b) clearly indicate that these movements were transmitted via the carrier on to the rack and the tie rods had a steering effect on the front wheels.

\section{CONCLUSIONS}

This article has presented a vehicle modelled in ADAMS that includes flexible suspension components such as the subframe and the lower control arms. The simulated vehicle shows a distinct deviation towards one side of the road during braking. In this case the vehicle drifts towards the left side. The simulation results have been compared with previously presented experimental data, and broad agreement has been demonstrated. The lateral reactions of the vehicle have been examined, and it was concluded that the main difference between the simulations and the experimental data was a higher degree of steering experienced by the instrumented vehicle, which resulted in greater magnitudes of lateral acceleration, displacement, yaw velocity, and steering wheel torque for the instrumented vehicle.

In conclusion, it can be said that among the suspension characteristics, toe steer angle shows the greatest influence on steering drift during braking. A cumulative effect of suspension parameters such as caster angle, KPI, and steering offset is seen through the steering axis moment that does not show a direct influence on toe angle. However, the wheels seem to react to a force other than that generated about the steering axis. Moreover, the deflection of the lower arm and the wheel has highlighted the effect of component deflection on suspension characteristics.

The major contribution towards toe steer angle is provided by the tie rods, which are affected by the steering rack forces. The movement of the toe steer angles corresponds to the push and pull forces induced by the tie rods. In the case presented here, the steering wheel was held fixed during braking; therefore, the predicted steering wheel torque shows a reaction within the steering column to the wheels and tie rod forces.

It has been shown that side-to-side variations occurring within the suspension due to component stiffness give rise to deflections that vary on either side of the suspension. The side-to-side variation of component deflection under dynamic condition affects suspension and steering characteristics and can cause instability during braking. The most significant influence of component deflections was noted for the front wheel toe steer angles, which were influenced by the lateral deflections of the steering carrier, gear, and tie rods.

Since the steering carrier is connected to the subframe, movements of the steering carrier suggest lateral movement of the subframe, therefore highlighting the lateral stiffness of the subframe under dynamic conditions. Moreover, the movements of the carrier are transmitted to the steering rack, which in turn affects the tie rods. The variation in side-to-side movement of the tie rods corresponds to the toe steer angle, thereby affecting the front wheels during braking, hence causing the vehicle to drift towards one side of the road. 


\section{REFERENCES}

1 Haataja, M. and Leinonen, T. On the distribution of braking forces in road braking, Oregon, USA. SAE paper 2000-01-3413, 2001.

2 Limpert, R. Brake design and safety, 2nd edition, 1999, p. 525 (SAE, Warrendale, PA).

3 Yamazaki, S., Fujikawa, T., and Yamaguchi, I. Influence of wheel alignment and tire characteristics on steering pull. In Proceedings of the JSAE Spring Conference, Japan, 1994, JSAE paper 9433074.

4 Marshall, P. Braking distribution and adhesion utilisation. Braking of Road Vehicles 2008, University of Bradford, UK, 2008.

5 Arbiol, J. and Catala, A. Steerability under straight braking with trucks and vans: a simulation approach. In Proceedings of the 14th European ADAMS User's Conference, Berlin, Germany, 1999, available from www.mscsoftware.com.

6 Aoki, A. and Nishimi, T. O. Recent trends in handling, stability and braking performance of Japanese passenger cars. In Proceedings of the 9th International Technical Conference on Experimental SafetyVehicles, Japan, 1982, SAE paper 826090.

7 Klaps, J. and Day, A. Steering drift and wheel movement during braking: parameter sensitivity studies. Proc. Instn Mech. Engrs, Part D:J. Automobile Engineering, 2003, 217, 1107-1115.

8 Lindenmuth, B. Tire conicity and ply steer effects on vehicle performance. SAE paper 740074, 1974.

9 Odier, J. Road-holding: braking and traction - European viewpoint. In Proceedings of the International Automobile Safety Conference, Detroit, Michigan, 1970, SAE paper 700367.

10 Todorovic, J. and Lenasi, J. Stochastic character of braking forces and its influence on vehicle lateral stability. In Proceedings of the 19th International FISITA Congress, 1982, 834016.

11 Banholzer, D. Improving directional stability under braking. In Proceedings of the 5th International Technical Conference on Experimental Safety Vehicles, London, UK, 1974.
12 Lenasi, J. and Todorovic, J. The stochastic approach to the lateral stability of vehicles under braking conditions. Braking of Road Vehicles, UK, paper no. C16/83, 1983.

13 Klaps, J. and Day, A. Steering drift and wheel movement during braking: static and dynamic measurements. Proc. Instn Mech. Engrs, Part D: J. Automobile Engineering, 2004, 219, 11-19.

14 Zhang, Y., Xiao, P., Palmer, T., and Farahani, A. Vehicle chassis/suspension dynamics analysis - finite element model vs. rigid body model. SAE paper 980900, 1998.

15 Yi, T. Vehicle dynamics simulations based on flexible and rigid multibody models. SAE paper 2000-01-0114, 2000.

16 Mirza, N., Hussain, K., and Day, A. Vehicle handling and stability investigation into causes of vehicle drift during straight-line braking. In Proceedings of the 2006 SAE World Congress, Detroit, Michigan, 2006, SAE paper 2006-01-0797.

17 Mirza, N., Hussain, K., Day, A., and Klaps, J. Investigation of dynamic characteristics of suspension parameters on a vehicle experiencing drift. Proc. IMechE, Part D: J. Automobile Engineering, 2005, 219, 1429-1441.

18 Reimpell, J. and Stoll, H. Automotive chassis: engineering principles, 1995, p. 410 (Edward Arnold, USA).

19 Ledesma, R. and Shih, S. The effect of kingpin inclination angle and wheel offset on medium-duty truck handling. SAE paper 2001-01-2732, 2001.

\section{APPENDIX}

\section{Notation}

$F_{\mathrm{b}} \quad$ braking force $(\mathrm{N})$

$r_{\mathrm{b}} \quad$ braking force moment arm (mm)

$r_{\mathrm{s}} \quad$ steering offset (scrub radius) $(\mathrm{mm})$

$M_{\mathrm{SA}} \quad$ moment about steering axis (Nm)

$\alpha \quad$ kingpin inclination (KPI) angle $\left(^{\circ}\right)$

$\delta \quad$ caster angle $\left(^{\circ}\right)$ 